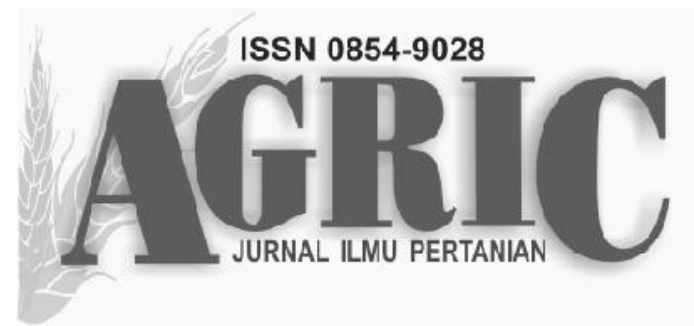

Fakultas Pertanian dan Bisnis Universitas Kristen Satya Wacana JI. Diponegoro 52-60 SALATIGA 50711 - Telp. 0298-321212 ext 354 email: agric_fpb@yahoo.co.id, website: ejournal.uksw.edu/agric

\title{
PERTUMBUHAN TIGA JENIS KIMPUL (Xanthosoma spp.) P PADA KETINGGIAN TEMPAT BERBEDA
}

\section{THE GROWTH OF THREE COCOYAM (Xanthosoma spp.) P ON THE DIFFERENT ALTITUDE}

\author{
Endang Anggarwulan \\ Jurusan Biologi FMIPA Universitas Negeri Sebelas Maret \\ Jl. Ir. Sutami - Surakarta \\ Widya Mudyantini \\ Jurusan Biologi FMIPA Universitas Negeri Sebelas Maret \\ J1. Ir. Sutami - Surakarta \\ Yuniar Nilawati \\ Jurusan Biologi FMIPA Universitas Negeri Sebelas Maret \\ Jl. Ir. Sutami - Surakarta
}

Diterima 7 Juli 2015, disetujui 10 Agustus 2015

\begin{abstract}
Indonesian society has a consumption pattern dominated staple grains group. To reduce dependence on other countries for imports of foodstuffs, need to diversification their meal using existing biodiversity. One of the crops that can be developed is the cocoyam (Xanthosoma spp.) potential as a source of carbohydrate. Cocoyam can be grown in the lowland to the mountains with a height of up to 1300 meters above sea level. Therefore it is necessary to find the most appropriate planting site so that plants can grow and develop optimally. This study aimed to determine the growth of three types of new cocoyam at a different altitude variation.

This study was conducted in two different regions of altitude, is Tawangmangu (1200 m above sea level) and Klaten (98 $\mathrm{m}$ above sea level). Observations using three different types of cocoyam, the tuber white, purple and yellow. Each type grown in both altitude with 10 replications each. The observations were obtained include fresh weight, dry weight, number of leaves, chlorophyll and carotenoid levels were analyzed by unpaired t test and ANOVA test at 95\% confidence level.

The results of this study indicate that tuber white, purple and yellow tuber are planted in the lowlands (Klaten) and highlands (Tawangmangu) had significant results in the measurement of plant height, fresh weight, dry weight, and chlorophyll and carotenoid levels have significantly different results, but not the parameters of the number of leaves. Height and weight of the fresh plant in Klaten higher than in Tawangmangu, while the white tuber dry weight in Tawangmangu higher than other treatments. The levels of chlorophyll and carotenoid yellow tuber is the highest in Klaten than others.
\end{abstract}

Keywords: altitude, cocoyam (Xanthosoma spp.), growth 


\section{PENDAHULUAN}

Indonesia sebagai negara berkembang dengan jumlah penduduk yang besar, menyebabkan kebutuhan akan bahan makanan pokok semakin meningkat. Pada saat ini Indonesia masih mengimpor bahan pangan tersebut dari negara lain. Diversifikasi makanan pokok diperlukan untuk mengurangi impor bahan pangan masyarakat yang didominasi padi-padian (padi, jagung, terigu). Perlu upaya peningkatan produksi pangan dengan cara mengembangkan dan memanfaatkan keanekaragaman hayati yang ada. Indonesia memiliki banyak tanaman pangan yang dapat dikembangkan dan dimanfaatkan lebih optimal, diantaranya adalah umbi-umbian yang berpotensi sebagai sumber karbohidrat. Umbi-umbian yang layak untuk dikembangkan sebagai tanaman pangan adalah kimpul (Xanthosoma sagittifolium (L.) Schott.) (Anggarwulan et al., 2008).

Penelitian terhadap tanaman tersebut mengenai karakter fisiologi antara lain kadar klorofil, karotenoid, belum banyak dilakukan. Karakter fisiologi tanaman sebagai pengaruh faktor lingkungan akan merupakan suatu pertimbangan untuk mengelola tanaman, agar diperoleh hasil yang maksimum (Basri, 2002). Hal ini penting untuk mendasari penelitian-penelitian lebih lanjut, terutama untuk budidaya dan peningkatan kandungan metabolit sekundernya.

Ketinggian tempat yang berbeda akan menyebabkan faktor lingkungan seperti suhu, intensitas cahaya, ketersediaan air, $\mathrm{CO}_{2}$ yang berbeda juga. Faktor-faktor tersebut mempengaruhi pertumbuhan tanaman antara lain adalah fotosintesis. Ketersediaannya dibutuhkan dalam jumlah tertentu sesuai dengan jenis tanaman. Penyinaran cahaya matahari sangat diperlukan tanaman ini dalam proses fotosintesis untuk menghasilkan bagian vegetatif (batang, daun, cabang, dan perakaran), generatif (bunga, buah dan biji). Kurangnya penyinaran matahari menyebabkan terhambatnya pertumbuhan dan produksi (Nasaruddin et al., 2006). Berdasarkan hal tersebut di atas penelitian ini bertujuan mengetahui pertumbuhan tiga jenis kimpul (Xanthosoma spp.) pada ketinggian tempat yang berbeda.

\section{METODE PENELITIAN}

\section{Bahan Penelitian}

Tiga jenis umbi kimpul (Xanthosoma spp.), air, tanah, pupuk kompos, aseton $80 \%, \mathrm{Na}_{2} \mathrm{SO}_{4}$, $\mathrm{CUSO}_{4}, \mathrm{H}_{2} \mathrm{SO}_{4}$, aquades, $\mathrm{NaOH}$, asam borat $4 \%$, metil merah $\mathrm{BCG}$ dan $\mathrm{HCl}$.

\section{Cara Kerja}

\section{Pertumbuhan}

Umbi ditanam pada media tanah dalam polibag dan ditumbuhkan selama 10 minggu. Pengamatan pertumbuhan meliputi tinggi tanaman, jumlah daun, berat basah, berat kering, kadar klorofil dan karotenoid.

\section{Pengukuran faktor abiotik}

Faktor abiotik yang diukur meliputi suhu, intensitas cahaya dan kelembaban udara. Pengukuran suhu, intensitas cahaya dan kelembaban udara dilakukan setiap minggu pada dua lokasi ketinggian yaitu $1200 \mathrm{~m}$ dpl di Tawangmangu dan $98 \mathrm{~m} \mathrm{dpl} \mathrm{di}$ Klaten.

\section{Analisis Data}

Data hasil pengamatan yang diperoleh meliputi berat basah, berat kering, jumlah daun, kadar klorofil dan karotenoid dianalisis dengan uji T tidak berpasangan dan uji ANOVA pada taraf kepercayaan $95 \%$.

\section{HASIL DAN PEMBAHASAN}

\section{Faktor Lingkungan}

Ketinggian tempat dan faktor-faktor lingkungan mempengaruhi pertumbuhan dan perkembangan suatu tanaman. Data faktor lingkungan di Tawangmangu (1200 m dpl) dan Klaten (98 m dpl) ditunjukkan pada Tabel 1.

Berdasarkan data di atas baik suhu, kelembaban maupun intensitas cahaya di Klaten dengan ketinggian $98 \mathrm{~m}$ dpl lebih tinggi dari pada Tawangmangu (1200 m dpl). Antara kedua tempat tersebut terdapat selisih suhu sekitar $6^{\circ} \mathrm{C}$. Selisih ini masih dalam batas toleransi tanaman tersebut. Begitu juga kelembaban dan intensitas cahaya. Intensitas cahaya di Tawangmangu (1200 m dpl) 
yang ketinggiannya lebih tinggi dibandingkan di Klaten adalah 30613 lux sedangkan di Klaten (98 m dpl) 44083 lux.

Tabel 1. Pengukuran faktor lingkungan (suhu, kelembaban udara dan intensitas cahaya) di Tawangmangu dan Klaten

\begin{tabular}{cccc}
\hline Lokasi & $\begin{array}{c}\text { Suhu } \\
\left({ }^{\circ} \mathrm{C}\right)\end{array}$ & $\begin{array}{c}\text { Kelembaban } \\
\text { Udara } \\
(\%)\end{array}$ & $\begin{array}{c}\text { Intensitas } \\
\text { Cahaya } \\
\text { (Lux) }\end{array}$ \\
\hline 1 & $24,76^{\text {a }}$ & 61,40 & 30613 \\
2 & $30,88^{\text {b }}$ & 70,00 & 44083 \\
\hline
\end{tabular}

Keterangan:

No 1. Tawangmangu; 2. Klaten. Angka yang diikuti huruf yang sama pada baris atau kolom yang sama menunjukkan tidak beda nyata pada taraf 5 persen.

\section{Tinggi Tanaman}

Data tinggi ketiga jenis kimpul pada dua lokasi ketinggian yang berbeda, ditunjukkan Tabel 2 berikut,

Tabel 2. Tinggi tiga jenis tanaman kimpul setelah 10 minggu pada variasi ketinggian $(\mathrm{cm})$

\begin{tabular}{cccc}
\hline \multirow{2}{*}{ No } & \multicolumn{3}{c}{ Jenis Umbi Kimpul } \\
\cline { 2 - 4 } & Putih & Ungu & Kuning \\
\hline 1 & $24.92^{\text {bc }}$ & $19.98^{\mathrm{b}}$ & $6.45^{\mathrm{a}}$ \\
2 & $55.94^{\mathrm{d}}$ & $58.16^{\mathrm{d}}$ & $33.58^{\mathrm{c}}$ \\
\hline
\end{tabular}

Keterangan:

No 1. Tawangmangu; 2. Klaten. Angka yang diikuti huruf yang sama pada baris atau kolom yang sama menunjukkan tidak beda nyata pada taraf 5 persen.

Hasil analisis menunjukkan bahwa ketinggian tempat mempengaruhi tinggi tanaman. Pada jenis yang berbeda terlihat bahwa umbi putih pada lokasi Tawangmangu ( $1200 \mathrm{~m} \mathrm{dpl})$ memiliki tinggi tanaman paling tinggi diikuti umbi ungu dan kuning, sedangkan pada lokasi Klaten $(98 \mathrm{~m} \mathrm{dpl})$ tertinggi adalah umbi ungu diikuti umbi putih dan yang terakhir umbi kuning. Pada lokasi 2 di Klaten terlihat lebih tinggi dibandingkan Tawangmangu untuk semua jenis. Pada dataran rendah memiliki intensitas cahaya yang lebih tinggi (44083 lux) dibandingkan Tawangmangu (30613 lux). Intensitas cahaya yang tinggi sangat diperlukan untuk aktifitas fotosintesis. Apabila aktifitas fotosinesis berjalan secara maksimal, maka tinggi tanaman sebagai hasil aktifitas fotosintesis dapat maksimal juga. Hal ini ditunjukkan oleh data ketinggian tanaman di Klaten lebih tinggi dari pada di Tawangmangu. Adapun di Tawangmangu mempunyai intensitas cahaya yang lebih rendah sehingga fotosintesisnya tidak maksimal, sehingga tinggi tanaman yang merupakan hasil aktifitas fotosintesis tidak maksimal.

Suhu di daerah Klaten lebih tinggi dibandingkan Tawangmangu. Suhu yang tinggi akan meningkatkan aktifitas enzim sehingga laju metabolisme semakin meningkat salah satunya adalah fotosintesis. Fotosintesis yang meningkat menyebabkan peningkatan asimilat. Hal ini menyebabkan pertumbuhan dan perkembangan tanaman meningkat. Penelitian ini sesuai dengan penelitian Kusumayadi dkk. (2013), yaitu tinggi tanaman maksimal sereh dapur (Cymbopogon citratus) dihasilkan pada lokasi tanam dataran rendah karena tanaman ini memerlukan cahaya matahari yang melimpah dan suhu tinggi untuk tumbuh dan berkembang dengan baik.

\section{Jumlah Daun}

Hasil pengamatan terhadap jumlah daun kimpul dapat dilihat pada Tabel 3 berikut,

Tabel 3. Jumlah daun kimpul setelah 10 minggu pada ketinggian berbeda

\begin{tabular}{cccc}
\hline \multirow{2}{*}{ No } & \multicolumn{3}{c}{ Jenis Umbi Kimpul } \\
\cline { 2 - 4 } & Putih & Ungu & Kuning \\
\hline 1 & 1.8 & 2.1 & 1.2 \\
2 & 1.5 & 2.1 & 1.8 \\
\hline
\end{tabular}

Keterengan:

1. Ketinggian $1200 \mathrm{~m}$ dpl (Tawangmangu)

2. Ketinggian $98 \mathrm{~m}$ dpl (Klaten).

Hasil Anava menunjukkan bahwa jumlah daun kimpul belum dipengaruhi perbedaan ketinggian penanaman. Jumlah daun terbanyak terdapat pada kimpul ungu baik yang ditanam di Tawangmangu (1200 $\mathrm{m} \mathrm{dpl}$ ) ataupun di Klaten (98 m dpl) yaitu dengan rata-rata 2,1. Adapun jumlah daun kimpul putih dan kimpul kuning menunjukkan jumlah daun yang hampir sama antara 2 lokasi tanam yang berbeda. Hal tersebut terjadi karena daun tanaman kimpul secara genetik tersusun hanya memiliki beberapa daun di setiap tangkainya dengan jumlah yang relatif sedikit. Hasil ini juga didukung dengan penelitian Hakim (2013), yang 
mengatakan bahwa jumlah daun Edamame di dataran tinggi dan dataran rendah menghasilkan jumlah daun yang sama.

\section{Berat Basah}

Data pengamatan menunjukkan bahwa berat basah ketiga jenis kimpul pada dua ketinggian tempat berbeda terdapat beda nyata, yang dapat dilihat pada Tabel 4 berikut,

Tabel 4. Berat basah kimpul setelah 10 minggu pada ketinggian tempat berbeda $(\mathrm{g})$.

\begin{tabular}{cccc}
\hline \multirow{2}{*}{ No } & \multicolumn{3}{c}{ Jenis Umbi Kimpul } \\
\cline { 2 - 4 } & Putih & Ungu & Kuning \\
\hline 1 & $130.57^{\mathrm{b}}$ & $120.7^{\mathrm{b}}$ & $40.95^{\mathrm{a}}$ \\
2 & $193.8^{\mathrm{c}}$ & $149.64^{\mathrm{bc}}$ & $47.82^{\mathrm{a}}$ \\
\hline
\end{tabular}

Keterangan:

No 1. Tawangman; 2. Klaten. Angka yang diikuti huruf yang sama pada baris atau kolom yang sama menunjukkan tidak beda nyata pada taraf 5 persen.

Berat basah tertinggi dimiliki oleh kimpul putih yaitu 193,8 g pada lokasi tanam dataran rendah yaitu $98 \mathrm{~m}$ dpl (Klaten). Selanjutnya diikuti dengan berat basah kimpul ungu dengan 149,64 di Klaten. Ketiga jenis kimpul yang ditanam di ketinggian $1200 \mathrm{~m}$ dpl (Tawangmangu) berat basahnya lebih rendah daripada Klaten. Terendah adalah kimpul kuning dengan berat 40,95 g pada lokasi $1200 \mathrm{~m}$ dpl. Berdasarkan data terlihat bahwa berat basah ketiga jenis kimpul lebih tinggi pada lokasi tanam di ketinggian $98 \mathrm{~m}$ dpl daripada $1200 \mathrm{~m}$ dpl.

Intensitas cahaya dan suhu yang lebih tinggi di Klaten dibandingkan di Tawangmangu, menyebabkan pertumbuhan tanaman yang dilihat dari nilai berat basah menjadi lebih tinggi. Hal ini sesuai dengan penelitian Harwati (2008), yang mengatakan bahwa perkembangan dan produksi tanaman kentang dapat dipengaruhi oleh panjang penyinaran dan suhu. Berat basah tanaman yang tinggi merupakan hasil penambahan fotosintat, yang digunakan untuk menambah jumlah dan ukuran sel. Tanaman herbaceus seperti kimpul sebagian besar massa akan tersimpan di akar (umbi) (Orcutt dan Nilsen, 1996)

\section{Berat Kering}

Data menunjukkan adanya beda nyata antara ketiga jenis kimpul maupun antara 2 lokasi yang berbeda. Rerata berat kering ketiga jenis kimpul pada lokasi tanam Tawangmangu (1200 m dpl) memiliki jumlah yang lebih besar daripada lokasi tanam Klaten (98 m dpl). Hal ini dapat dilihat pada Tabel 5 bawah ini.

Tabel 5. Berat kering kimpul setelah 10 minggu pada ketinggian berbeda $(\mathrm{g})$.

\begin{tabular}{|c|c|c|c|}
\hline \multirow{2}{*}{ No } & \multicolumn{3}{|c|}{ Jenis Umbi Kimpul } \\
\hline & Putih & Ungu & Kuning \\
\hline 1 & $12.76^{b}$ & $11.66^{\mathrm{b}}$ & $4.02^{\mathrm{a}}$ \\
\hline 2 & $10.05 \mathrm{~b}$ & $9.53 \mathrm{~b}$ & $1.37^{\mathrm{a}}$ \\
\hline \multicolumn{4}{|c|}{$\begin{array}{l}\text { Keterangan: } \\
\text { 1. Ketinggian } 1200 \mathrm{~m} \mathrm{dpl} \text { (Tawangmangu); } \\
\text { 2. Ketinggian } 98 \mathrm{~m} \mathrm{dpl} \text { (Klaten). } \\
\text { Angka yang diikuti huruf yang sama pada baris atau } \\
\text { kolom yang sama menunjukkan tidak beda nyata } \\
\text { pada taraf 5\%. }\end{array}$} \\
\hline
\end{tabular}

Ketiga jenis kimpul, kimpul putih memiliki berat kering yang tertinggi dengan berat $12,76 \mathrm{~g}$ pada ketinggian $1200 \mathrm{~m} \mathrm{dpl}$ (Tawangmangu) dan 10,05 g pada ketinggian $98 \mathrm{~m}$ dpl (Klaten). Diikuti dengan kimpul ungu 11,66 g pada lokasi Tawangmangu dan 9,53 g pada lokasi Klaten yang terakhir adalah kimpul kuning dengan 4,02 g pada lokasi Tawangmangu dan 2,37 g pada lokasi Klaten.

Jika dilihat dari data berat basah (Tabel 4), maka tiga jenis tanaman kimpul di Tawangmangu menunjukkan berat basah yang lebih rendah dibanding di Klaten. Adapun berat keringnya menunjukkan fenomena yang berbeda yang di Tawangmangu justru lebih tinggi. Hal ini disebabkan karena di Tawangmangu umbi (root) yang dihasilkan lebih besar-besar dibanding Klaten dan shoot (pelepah dan daun) lebih kecil. Bagian shoot adalah bagian yang herbaceus sehingga setelah dikeringkan beratnya menjadi sangat rendah karena air banyak menguap selama proses pengeringan. Hal ini sesuai dengan penelitian Kusumayadi dkk (2013) yang menunjukkan bahwa berat basah yang tinggi pada Cymbopogon citratus justru berat keringnya rendah.

\section{Kadar Klorofil dan Karotenoid}

Data hasil pengamatan kadar klorofil total ketiga jenis kimpul pada ketinggian penanaman yang berbeda menunjukkan adanya beda nyata. Perbedaan ketinggian tempat mempengaruhi 
kadar klorofil daun kimpul. Pada kimpul putih yang ditanam di Klaten $(98 \mathrm{~m} \mathrm{dpl})$ dan di Tawangmangu $(1200 \mathrm{~m} \mathrm{dpl})$ memiliki kadar klorofil paling sedikit dibandingkan kedua jenis yang lain. Hasil pengamatan klorofil menunjukkan perbedaan yang tidak terlalu besar antara kimpul yang ditanam di ketinggian $98 \mathrm{~m}$ dpl dengan $1200 \mathrm{~m}$ $\mathrm{dpl}$, hal ini ditunjukkan pada Tabel 6 berikut,

Tabel 6. Kadar klorofil kimpul setelah 10 minggu pada ketinggian berbeda $(\mu \mathrm{mol} / \mathrm{ml})$

\begin{tabular}{cccc}
\hline \multirow{2}{*}{ No } & \multicolumn{3}{c}{ Jenis Umbi Kimpul } \\
\cline { 2 - 4 } & Putih & Ungu & Kuning \\
\hline 1 & $9.77^{\mathrm{ab}}$ & $13.71^{\mathrm{bc}}$ & $13.48^{\mathrm{bc}}$ \\
2 & $9.19^{\mathrm{a}}$ & $13.95^{\mathrm{bc}}$ & $17.07^{\mathrm{c}}$ \\
\hline
\end{tabular}

Keterangan:

1. Ketinggian $1200 \mathrm{~m}$ dpl (Tawangmangu)

2. Ketinggian $98 \mathrm{~m}$ dpl (Klaten). Angka yang diikuti huruf yang sama pada baris atau kolom yang sama menunjukkan tidak beda nyata pada taraf $5 \%$.

Pada kimpul jenis umbi putih di Klaten memiliki kadar klorofil total yang lebih rendah dari yang ditanam di Tawangmangu, namun sebaliknya pada jenis umbi ungu dan kuning di Tawangmangu lebih tinggi kadarnya daripada di Klaten. Bahkan untuk umbi kuning di Tawangmagu, klorofil totalnya paling tinggi dibandingkan yang lain. Diperkirakan pada tempat dengan ketinggian yang lebih tinggi tanaman memperoleh radiasi sinar UV-B yang berlebih, dan hal ini dapat mempengaruhi pertumbuhan. Radiasi ultraviolet dapat menyebabkan tanaman kehilangan beberapa bentuk fungsi dari organel, khususnya kloroplas sebagai sumber produksi energi. Perubahan yang terjadi dapat ringan maupun berat, tergantung pada spesies tumbuhannya, karena radiasi ultraviolet memiliki efek yang berbeda pada berbagai spesies tanaman (Pilon dan Criscuolo, 2009).

Kadar karotenoid dalam penelitian ini menunjukkan tidak ada perbedaan yang signifikan antar jenis umbi maupun tinggi tempat tumbuh pada semua perlakuan, kecuali pada jenis umbi kuning di dataran rendah (Klaten) kadarnya cukup tinggi yaitu $17 \mu \mathrm{mol} / \mathrm{ml}$. Adapun data kadar karotenoid dapat dilihat pada Tabel 7.
Tabel 7. Kadar karotenoid kimpul setelah 10 minggu pada ketinggian berbeda $(\mu \mathrm{mol} / \mathrm{ml})$.

\begin{tabular}{cccc}
\hline & \multicolumn{3}{c}{ Jenis Umbi Kimpul } \\
\cline { 2 - 4 } & Putih & Ungu & Kuning \\
\hline 1 & $0.11^{\mathrm{a}}$ & $0.13^{\mathrm{a}}$ & $0.13^{\mathrm{a}}$ \\
2 & $0.10^{\mathrm{a}}$ & $0.12^{\mathrm{a}}$ & $0.17^{\mathrm{b}}$ \\
\hline
\end{tabular}

Keterangan:

No 1. Tawangmangu; 2. Klaten. Angka yang diikuti huruf yang sama pada baris atau kolom yang sama menunjukkan tidak beda nyata pada taraf 5 persen.

Berdasarkan hasil penelitian, parameter tinggi tanaman, berat segar, berat kering, kadar klorofil total dan karotenoid menunjukkan beda nyata antar jenis umbi pada ketinggian tempat yang berbeda, namun tidak demikian halnya pada parameter jumlah daun.

Tanaman yang tumbuh pada ketinggian yang tinggi biasanya memiliki ciri-ciri morfologi yang khas, termasuk pertumbuhan yang kerdil (Bresson et al., 2011). Hal ini terjadi karena terdapat penyesuaian morfologi dan fisiologis yang memungkinkan individu untuk bertahan dalam lingkungan tercekam yang dikaitkan dengan ketinggian tempat tumbuh. Kondisi ekologi seperti air, suhu, dan intensitas cahaya berpengaruh langsung pada pertumbuhan vegetatif tanaman. Tanaman akan mengubah terutama pertumbuhan vegetatif, seperti luas daun, jumlah stomata dan batang dan tunas untuk beradaptasi pada kondisi yang berbeda. Hasil penelitian ini sejalan dengan hasil penelitian Aslantas dan Karakurt (2009) pada varitas apel yang ditanam pada ketinggian yang berbeda juga menunjukkan pertumbuhan tajuk yang berbeda. Pada ketinggian yang lebih rendah pertumbuhan tajuk lebih tinggi. Dengan meningkatnya ketinggian lahan, maka curah hujan juga meningkat namun suhu, $\mathrm{O}_{2}$ dan volume $\mathrm{CO}_{2}$ menurun.

Data berat basah dan berat kering menunjukkan hasil yang berlawanan pada berat kering setiap tanaman di Tawangmangu lebih tinggi dibanding dengan yang ditanam di Klaten. Hal tersebut dikarenakan perkembangan antara tajuk dengan umbi umumnya saling berlawanan. Tingginya tajuk akan diimbangi dengan rendahnya pertumbuhan bagian bawah tanah. Sebagian besar tajuk kimpul 
mengandung banyak air di tangkai dan helaian daun, sehingga pada saat pengeringan terjadi banyak kehilangan air.

Peningkatan suhu lingkungan di Klaten meningkatkan laju pertumbuhan kimpul hal tersebut berkaitan dengan suhu lingkungan masih berkisar antara $24-30^{\circ} \mathrm{C}$ yang masih merupakan kisaran suhu optimum. Hasil tersebut ditunjukkan pada tabel pengukuran faktor lingkungan (Tabel 1).

Idso et al., (1987) meneliti pengaruh peningkatan suhu dan $\mathrm{CO}_{2}$ terhadap pertumbuhan sejumlah tanaman air dan darat. Peningkatan 300 ppm konsentrasi $\mathrm{CO}_{2}$ meningkatkan pertumbuhan tanaman sekitar $30 \%$ tetapi efek tersebut juga tergantung pada suhu.

\section{KESIMPULAN}

1. Hasil penelitian menunjukkan bahwa ketinggian tempat dan jenis kimpul berpengaruh terhadap semua parameter pertumbuhan kecuali jumlah daun. Pada dataran rendah (Klaten) tinggi tanaman dan berat basah lebih tinggi dibandingkan pada dataran tinggi (Tawangmangu), sedangkan berat kering pada umbi putih di daerah Tawangmangu lebih tinggi dibandingkan perlakuan yang lain.

2. Jenis umbi kuning di Klaten memiliki kadar klorofil dan karotenoid paling tinggi dibandingkan jenis yang lain.

\section{DAFTAR PUSTAKA}

Anggarwulan, E., Solichatun dan W. Mudyantini. 2008. Karakter fisiologi kimpul (Xanthosoma sagittifolium(L.) Schott) pada variasi naungan dan ketersediaan air. Biodiversitas 9 (4): 264-268

Aslantas, R and H. Karakurt. 2009. The Effects of altitude on stomata number and some vegetative growth parameters of some apple cultivars. Research Journal of Agriculture and Biological Sciences, 5(5): 853-857
Basri, J. H. 2002. Agroekologi. Jakarta: PT Raja Grafindo Persada.

Bresson, C.C., Y. Vitasse, A. Kremer, S. Delzon. 2011. To what extent is altitudinal variation of functional traits driven by genetic adaptation in European oak and beech? Tree Physiology Online at http://www.treephys.oxfordjournals.org. Tree Physiology 00,1-11.

Hakim, N.A. 2013. Perbedaan kualitas dan pertumbuhan benih edamame varietas ryoko yang diproduksi di ketinggian tempat yang berbeda di Lampung. Jurnal Pertanian Terapan 13 (1): 8-12.

Harwati, C.T. 2008. Pengaruh suhu dan panjang penyinaran terhadap umbi kentang (Solanum tuberosum,ssp). Jurnal Inovasi Pertanian 7 (1): 11-18.

Idso, S.B., B.A. Kimball, M.G. Anderson, J.R. Mauney.1987. Effects of atmospheric $\mathrm{CO}_{2}$ enrichment on plant growth: the interactive role of air temperature. Agriculture, Ecosystem \& Environment 20 (1): $1-10$

Kusumayadi, I.W.H, I.M. Sukewijaya, I.K Sumiartha, N.S. Antara. 2013. Pengaruh ketinggian tempat, mulsa dan jumlah bibit terhadap pertumbuhan dan rendemen minyak sereh dapur (Cymbopogan citratus). E-Jurnal Agroekoteknologi Tropika 2 (1): 49.

Nasaruddin, 2006. Fotosintesis, Respirasi dan Analisis Pertumbuhan Tanaman. Fakultas pertanian dan kehutanan Unhas.

Orcutt, D.M and Nilsen, E.T.1996. Physiology of Plants Under Stress: Abiotic Factors. John Wiley \& Sons.Inc. Canada.

Pilon, D.J. and C.L. Criscuolo. 2009. Effects of Ultraviolet-B Radiation on Photobiology. www.vitamindwiki.com/tiki-download (diakses 26 November 2011). 